\title{
Understanding the Nuance in Disciplinary Self-Efficacy
}

\author{
Vashti Sawtelle $^{1,2}$ and Angela Little ${ }^{1}$ \\ ${ }^{I}$ Michgian State University, Lyman Briggs College \\ ${ }^{2}$ Department of Physics \& Astronomy \\ 567 Wilson Rd, East Lansing, MI, 48824
}

\begin{abstract}
Educational psychology studies have linked self-belief constructs to success in STEM, including self-efficacy (the belief in one's ability to succeed at specific tasks). However, most of the work with these constructs uses traditional psychology large-N quantitative studies to show that change happens without describing in qualitative detail the mechanism by which it happens. This paper will focus on a case study of a student who sees herself as competent in neuroscience, identifies as a math person, but still places physics in a category of special difficulty. Evidence from this case suggests that receiving grade-based evidence of her capability in physics is insufficient for impacting her self-beliefs in physics. We explore ways in which a nuanced understanding of how a sense of capability develops helps us understand this student's disciplinary self-efficacy.
\end{abstract}

PACS: 01.40.Fk, 01.40.gb, 01.30.Cc

\section{INTRODUCTION}

At the undergraduate level, a student's self-efficacy (their sense of capability in a particular area) has been shown to be tightly connected to student success in science classes. Self-efficacy has been linked to higher rates of persistence and retention in STEM courses across the country [1] and has been shown to be a better predictor of persistence in math majors than level of interest in the subject or past achievements. In our own work we have also shown that student self-efficacy is a significant predictor of success in introductory physics [2].

While self-efficacy, as a construct, has been linked to retention and success for students, the primary methods of study have been clinical psychological settings. Although important conclusions can be drawn from these settings, they are limited in allowing for opportunities to examine the mechanism by which students develop a sense of capability. For example, the self-efficacy studies on student retention in science come primarily from surveys administered in introductory psychology classrooms $[3,4]$ and clinical interview settings $[5,6]$. In physics, the work on self-efficacy has primarily relied on pre/post testing around a particular course experience $[7,8]$.

In this paper we begin work to conceptualize selfefficacy in a more nuanced way to aide in unpacking how self-efficacy develops. The nuance we bring to selfefficacy takes three forms: (1) we examine how "science" students have distinct disciplinary distinctions in the ways they think of their capability, (2) we consider how a student's perspective on what it means to "know" or "understand" in physics interacts with their sense of capability, and (3) we explore how student interests may impact a sense of capability in physics. In what follows, we lay out more explicitly the traditional work examining selfefficacy, point out ways to push on this traditional work, and present student data that begins to unpack the nuance in self-efficacy in physics.

\section{OUR THEORETICAL LENS}

Self-efficacy was first developed as an integral part of a theoretical framework attempting to explain how behavioral change takes place [9]. The concept of self-efficacy is defined as the confidence in one's own ability to perform a particular task. Within social cognitive theory, self-efficacy determines the courses of action an individual will take. People with high self-efficacy for a particular task will be more likely to choose a path that requires the performance of that task, to persevere in the task over long periods of time, and to persist in the face of difficulties. The utility in understanding the role of self-efficacy in academics then lies in the assumption that students with high academic selfefficacy are more likely to succeed in school, to choose career paths that require success in academics, and to choose majors that align with their beliefs about personal capabilities. In particular, researchers have focused attention on science as an area that traditionally has low interest and persistence rates. Studies have shown that selfefficacy is able to predict a university student's persistence in science majors as well as science career choices $[10,11]$.

Researchers have also investigated how self-efficacy can predict achievement in science for high school [12] and university students [10]. In past work Sawtelle found that a student's self-efficacy in physics at the beginning of an introductory physics course predicts the likelihood of a student passing that same course [2]. Further, in a Modeling Instruction physics classroom, Sawtelle found that students' physics self-efficacy is positively impacted after one semester of the course [7].

While considerable research has been done to investigate the relationship between self-efficacy and these outcome variables, fewer investigators have studied the 
development of self-efficacy. Bandura, in his initial proposal for the construct of self-efficacy, outlined four experiential sources that would impact a sense of capability: mastery experiences, vicarious learning experiences, social persuasion experiences, and physiological experiences [6]. Within the smaller body of literature on the development of self-efficacy, much of the research focuses on confirming the relationship between the four experiential sources and self-efficacy itself $[12,13]$. Researchers have tried to determine if factors such as gender or particular tasks change the types of information drawn upon in judging selfefficacy (e.g. [12]).

Regardless of the focus, the majority of the research takes place by developing quantitative surveys that use researcher-derived experiences as stand-ins for the theoretically posited sources of self-efficacy [4,12]. The limitation with these methods is that it does not leave room for researchers to uncover additional factors that people may draw on when judging their capability. A few researchers have turned to qualitative methods, but the majority of this work continues to focus on confirming or disconfirming the four experiential sources (originally proposed by Bandura) rather than exploring additional impacts $[5,6,13]$.

In our current work, we are exploring the ways in which students develop a sense of capability. In this work we try to move beyond survey measurements of self-efficacy, and we do not limit our attention to the traditional sources of self-efficacy. In our work, we attend to the variety of ways that students evaluate their sense of capability, as well as how that sense of capability depends on the science discipline (e.g. biology, chemistry, physics).

\section{EXAMING SELF-EFFICACY THROUGH INTERVIEW STUDY}

The Lyman Briggs College (LBC) is a residential college, within the Michigan State system, that focuses on the study of science and its impacts on society. All students in LBC enroll in all the introductory science courses, as well as courses on the history, philosophy, and sociology of science. Cross-disciplinary collaboration is a key hallmark of the LBC and for the past three years, the introductory physics courses have been focused on developing connections with the life sciences. Nearly all of the students in LBC major in the natural sciences, about $60 \%$ are women, and nearly $20 \%$ are from historically underrepresented groups.

In the early parts of this study we were interested in understanding the experiences of students in LBC's introductory physics for the life sciences (IPLS) course. The second author conducted interviews with students at the end of the fall and spring semesters of this two-semester introductory sequence. Both interviews were designed to explore student experiences in the course. The second interview focused more explicitly on understanding the disciplinary self-efficacy that students feel around their biological science courses in contrast to their physics classes. Our primary research question in this study became: How do students who see themselves as good at "science" simultaneously see themselves as not good at physics?

In this paper we focus on the data from a single student, who we will call "Anna." We conducted two interviews with Anna, one at the end of each semester of introductory physics. Anna was a high-performing student during both semesters. In conjunction with taking the two-semester sequence she completed an honors project related to the history of women in physics and astronomy. Anna is a life science major with a women's and gender studies minor. She entered the university-level class having taken one physics course in high school, which she refers to as "baby physics." In the following sections we outline the ways in which we understand Anna's sense of capability to be discipline specific, to be influenced by her understanding of what it means to "know" in physics, and to be impacted by connections to her other interests.

\section{THE NUANCE IN SELF-EFFICACY}

In the traditional educational psychology view on evaluating a student's self efficacy, researchers would ask students to respond on a Likert scale to a statement similar to "I feel capable of succeeding in science." What we aim to highlight in the following data from Anna is that, for some students, answering this question is a complicated endeavor that relies on a number of factors.

\section{A. Anna's Sense of Capability is Discipline Specific}

Early in the interviews it is clear that Anna sees herself as a science person, who is typically good at (and enjoys) biology and math. In interviews she describes,

"I like more of the biology and I like more of the psych. Obviously, doing psychology and neuroscience and sociology kind of stuff." (Sem 1)

"I like math and math came fairly easily. And I like the logical progression of math....But math [has] always come fairly easily. It's like 'Yeah, I'm a math-ish person." " (Sem 2)

However, despite her sense of self as a science person, in both interviews Anna consistently describes herself as not as good at physics,

"I was used to the biology, or even sociology, and psych in between [taking physics in HS and college]. So then I got directed into that train of thought, which is very different than physics....I found a lot of physics concepts are counter-intuitive to what I think." (Sem 1)

"It [physics] was just a really rough class for me."(Sem 1) 
"I would say I'm better at physics, or I have a better...I'm not as scared of it, or not intimidated by it anyway. But I wouldn't go anywhere and [say], 'I took a physics class and I know what I'm talking about.' Whereas I would in neuroscience." (Sem 2)

It is important to note at this point that Anna is actually quite successful in her introductory physics class. During her interview, she acknowledges that she has between a $\mathrm{B}+$ and an $\mathrm{A}$ in the course both semesters, but still feels lacks confidence about her capability in the discipline. This is clearly positioned in contrast to her sense of capability in other areas such as neuroscience, biology, and psychology. This data supports the view that it is important to look at student self-efficacy in disciplinary-specific ways.

\section{B. Anna's Sense of Capability Depends on Her Understanding of What Counts as Knowing in Physics}

Given that Anna's experiences with physics primarily came from course settings, we look to her experiences with homework and exams to unpack how she understands what counts as knowing. In this realm of experiences we see a consistent description from Anna:

"I did fine in the class - I'm pretty sure I did a $[\mathrm{B}+]$ or [A], but it was hard. It terms of getting my brain to work like that." (Sem 1)

"I still wouldn't consider myself necessarily capable. Which is really depressing, because if you look at my grades they're fine. Obviously I can do physics, but I don't feel confident in the concepts." (Sem 2)

We see that Anna receives information from the class (in the form of grades) that she is doing well in the course. However, this information is insufficient to make her feel confident in her ability to do physics. When we explore this a bit more closely we find Anna describing a feeling that she doesn't really understand the physics:

"I think I understood the concepts in terms of using the definitions, or even applying the math formulas in words. But I think that's just...I tend to be good with words, or B.S. better. Or I have a tendency to talk my way into the right answer." (Sem 2)

Instead of just relying on her grade from the professor, Anna describes valuing being able to apply the math and explain equations in words in her physics class. However, she devalues what she describes as her ability to "talk [her] way into the right answer," which she also refers to as being able to "B.S." Later she unpacks what she means by that a little more saying,

"So it's probably not really B.S.'ing, it's probably just remembering the concepts. But to me, I wasn't confident. I wasn't like, 'This is exactly what happens.' So to me it felt like cobbling ideas together and just hoping the right words fit." (Sem 2)

Anna contrasts this with her classmates who would, "...ask questions in class and there would be a formulated...they could formulate an answer to why something worked a certain way...it came across in class like, 'I thought I should know that, but I don't. So does that make me behind? Or does that mean other people are still in my pool? Or what?"' (Sem 2)

In these quotes we see elements of what Anna thinks it means to really understand physics. It is insufficient to simply get good grades, or even to "talk her way" to the right answer. Instead, she suggests that understanding physics would mean knowing "exactly what happens" and being able to formulate clear answers to "why something worked a certain way." She positions these ways of knowing in contrast with "cobbling ideas together" or "applying the math ideas in words." This is particularly troubling because the course emphasized these other ways of knowing in physics (which is likely why she was receiving high grades in the course). Anna's view on what it means to really know physics kept her from describing herself as capable in the course. In other words, there seems to be an interaction between Anna's epistemological view of physics, and her sense of capability in physics.

\section{Anna's Interests Impact Her Sense of Capability}

In this last data section we explore how Anna's interests played a role in impacting her self-efficacy. The physics course that Anna was enrolled in was designed to highlight connections between physics and the life sciences. It was our expectation that connecting across these two areas of science would change the kind of experiences students had in physics [14]. We did see some elements of these connections showing up for Anna,

"In [physics 1], I liked the way it was structured because it looked for different connections between the sciences....And it worked a lot in terms of diffusion and how that works within cells. Stuff that I already knew about that happened in biology... but how does it actually physically work?"(Sem 2)

However, these connections for Anna seemed to be superfluous. She goes on to say,

"There were a lot of [places] where I could see it working, but I tried to just understand the physics part of things instead of looking too deeply for connections at this point.'(Sem 1)

In Anna's case, it doesn't seem as though seeing connections between biology and physics helped her feel like she was more capable in the class. Instead, she saw the connections as something to examine after she understood the physics part.

What did seem to stand out to Anna was an honors project she completed in conjunction with the course on the history of women in physics. The honors project is an opportunity available to any student enrolled in the course, and is described as a way for students to explore a topic more in- 
depth with guidance from the instructor. Anna, as a women's and gender studies minor, proposed researching the history of women in physics and astronomy and writing a research report. As she completed the project, the first author (her mentor on the honors project) encouraged her to participate in a local undergraduate research poster session. During the interview with Anna in the second semester, a portion of the discussion was devoted to exploring this experience. In this setting Anna describes the honors project changing the way she interacted with physics,

"When I went in and pitched the idea for the honor's option [the professor] was really excited about it... Obviously this is something I care about, and I don't particularly care about physics." (Sem 2)

"I really liked [my project]. It made physics 2, I think, easier. In the sense that it made it easier for me to view physics as something interesting and not just a class." (Sem 2)

"[the project showed] obviously there's women doing physics - like physics, like not just blocks and ramps, but actually colliding things together and seeing what happens — and that just blew my mind.... I didn't even know that was physics necessarily." (Sem 2)

Unlike the course-structured connections between the life science and physics, this honor's project that Anna completed seemed to have a significant impact on Anna's experience with physics. Though we are unable to say with certainty that her confidence in herself in physics was impacted. In these few quotes we see how her ideas of what counts as physics was impacted - "I didn't even know that [colliding things together] was physics", as well as her sense of capability in her physics course - "It made physics 2 easier." While generating this interest is part of the intention of the honor's project, it was surprising to see how much more the self-structured project impacted Anna's evaluation of her ability compared to the course sanctioned connections with the life sciences.

Ultimately, even though Anna notes that physics is "easier" because of her honors option experience, her understanding of what counts as knowing in physics seems

[1] K. Multon, S. Brown, and R. Lent, J. Counsel. Psych. 38, 30-38 (1991).

[2] V. Sawtelle, E. Brewe, and L. H. Kramer, J. Res. Sci. Teach. 49, 1096-1121 (2012).

[3] N. Betz and G. Hackett, J. Counsel. Psych., 28, 399410 (1981).

[4] R. Lent, F. Lopez, and K. Bieschke, J. Counsel. Psych. 38, 424-430 (1991).

[5] A. L. Zeldin and F. Pajares, Amer. Educ. Res. J. 37, 215-246 (2000).

[6] A. Zeldin, S. Britner, J. Res. Sci. Teach. 45, 10361058 (2008). to have a greater influence on her overall judgments of her capability in physics.

\section{DISCUSSION}

We do not present this case study examining a single student's understanding of their capability in physics to make a generalized claim about how self-efficacy develops. Instead, we present this case as a way of examining how we might move beyond the traditional views of self-efficacy. With this case we've begun to explore the ways in which other constructs, such epistemology and interest, may be impacting a student's sense of capability. Seeing Anna position herself as very capable in neuroscience and math, while not capable in physics was striking for us in contrast with the typical ways that self-efficacy in science is viewed. In unpacking how Anna evaluated her sense of capability, we uncovered ways that her views on understanding and knowing in physics could be directly impacting her sense of capability. If Anna had instead believed that knowing in physics meant explaining ideas in words, and being able to cobble together explanations - how might her sense of capability be different? Additionally, when comparing Anna's experience with biology examples in physics class versus her honors project, this case makes us wonder how structuring opportunities for students to connect their own interests to physics courses might impact their self-efficacy.

What we have not done in this work is to make a case that epistemology and interest are constructs that should be consequential for student self-efficacy. However, we do believe this work raises the question of whether we should be viewing constructs as independent of each other (as traditional pre/post measure and regression analyses typically would), or whether we should be finding ways of understanding the interactions between these variables.

\section{ACKNOWLEDGEMENTS}

We are grateful to the students who participated in this study, conversations around this work with PERL@MSU group, and the Lyman Briggs College for supporting this research.

[7] V. Sawtelle, E. Brewe, and L. H. Kramer, in PERC 2010 Proc., pp. 289-292.

[8] K. A. Shaw, in PERC 2003 Proc., pp. 137-140.

[9] A. Bandura, Psych. Rev. 84, 191-215 (1977).

[10] R. W. Lent, S. D. Brown, and K. C. Larkin, J. Counsel. Psych. 33, 265 (1986).

[11] D. Luzzo, P. Hasper, K. Albert, M. Bibby, and E. Martinelli Jr, J. Counsel. Psych. 46, 233-243 (1999).

[12] S. L. Britner, J. Res. Sci. Teach. 45, 955-970 (2008).

[13] R. Lent, S. Brown, and M. Gover, J. Career Couns. (1996).

[14] V. Sawtelle and C. Turpen, Arxiv.org, 1-38 (2014). 